\title{
Endoscopic management of cysticercal cysts within the lateral and third ventricles
}

\section{Marvin Bergsneider, M.D., Langston T. Holly, M.D., Jae Hong Lee, M.D., Wesley A. King, M.D., and John G. Frazee, M.D.}

Harbor-UCLA Medical Center and Division of Neurosurgery, University of California at Los Angeles, Los Angeles, California; and Department of Neurosurgery, Mt. Sinai School of Medicine, New York, New York

In this report the authors review their 3-year experience with the endoscopic management of patients with hydrocephalus who harbored cysticercal cysts within the third and lateral ventricles. The management plan was to utilize an endoscopic approach to remove the cysts and to incorporate techniques useful in treating obstructive hydrocephalus. The ultimate goals were to avoid having to place a complication-prone cerebrospinal fluid shunt and to eliminate the risk of complications related to cyst degeneration.

A retrospective analysis of 10 endoscopically managed patients with hydrocephalus and cysticercal cysts within the third or lateral ventricles was performed. A general description of the instrumentation and the technique used for removal of the intraventricular cysts is given. At presention, neuroimaging revealed findings suggestive of obstructive hydrocephalus in eight patients.

Seven of the 10 patients treated endoscopically were spared the necessity of shunt placement. Three successful third ventriculostomies and one therapeutic septum pellucidotomy were performed. Despite frequent rupture of the cyst walls during removal of the cyst, there were no cases of ventriculitis. The endoscopic approach successfully allowed removal of a cyst situated in the roof of the anterior third ventricle. One patient suffered from recurrent shunt obstructions secondary to a shunt-induced migration of cysts from the posterior fossa to the lateral ventricles.

The endoscopic removal of third and lateral ventricle cysticercal cysts, combined with a third ventriculostomy or septum pellucidotomy in selected cases, is an effective treatment in patients with hydrocephalus and should be considered the primary treatment for this condition.

Key Words * cysticercosis * brain cyst * endoscopy * hydrocephalus * third ventriculostomy

Based on epidemiological estimates, approximately 2.4 million people worldwide harbor neurocysticercal cysts within the lateral and third ventricles.[24,28,30,37] Involvement of the ventricular 
system is generally associated with higher rates of patient morbidity and mortality relative to the parenchymal manifestation.[1,4,11,15,26,28,31,36] In a report by Zee, et al.,[38] six of 46 patients harboring intraventricular cysts died of acute hydrocephalus shortly after admission to the hospital. In five of these patients cysts only involved the lateral ventricle.

No clear consensus can be inferred from the literature as to the optimum management of intraventricular cysticercosis involving the lateral and third ventricles. In general, there are three options: anthelmintic therapy, cerebrospinal fluid (CSF) diversion, and/or surgical removal of the cyst. If the patient has symptomatic hydrocephalus, surgery is generally the only option. Many practitioners have favored the placement of a CSF shunt as the initial and definitive treatment $[4,8,26]$ based on the rationale that most patients would eventually require a CSF shunt regardless of any other treatment plan chosen. In addition, compared with an open craniotomy that requires retraction of the brain for visualization of the ventricular system, a CSF shunt is generally thought to be a simpler, less traumatic, and safer procedure. This recommendation for a CSF shunt has been made despite the known fact that the shunt puts the patient at risk for complications, including ventriculitis, meningitis, mass effect due to enlarging cyst, catheter obstruction by a cyst,[33] or shunt failure for other reasons.[8]

Beginning in 1995, one of the primary goals of our approach to the management of intraventricular cysticercosis has been to avoid placing a CSF shunt. As a secondary goal, we wished to minimize the overall morbidity related to cyst degeneration, cyst expansion, and/or shunt failure if a shunt was required. To accomplish this goal, we chose to perform endoscopically guided removal of all cysts from within the lateral and third ventricles when possible and then to reestablish internal CSF flow pathways when indicated. This report details our experience, both technical successes and failures, with this management plan. The management of fourth ventricular cysts will be addressed in a separate report.

\section{CLINICAL MATERIAL AND METHODS}

\section{Patient Population}

This report constitutes a retrospective analysis of the records of 10 patients treated at three Medical Centers: eight patients at Harbor-UCLA Medical Center, one at UCLA Medical Center, and one at Mt. Sinai Medical Center in New York City. These were unselected cases representing all patients with known or suspected cysticercal cysts within the third and/or lateral ventricles treated at these institutions from September of 1995 through December of 1998. The mean patient age was 39 years (range 21-72 years). All patients were men and immigrants from countries where cysticercosis is endemic.

\section{Presenting Symptoms}

All patients presented with symptoms and signs referable to hydrocephalus, including headache, nausea, and vomiting. The duration of symptoms ranged from 5 days to several years. One patient (Case 1; Table 1) in whom a known cyst was located in the right occipital horn of the lateral ventricle had been followed for 3 years (Fig. 1). He then presented with a 1-week history of increasing headaches, nausea, and vomiting and was found to have an interval enlargement of his ventricles with no apparent change in the cyst location. One patient (Case 6) was found unresponsive following an 8-year history of headache. Prior to a ventriculostomy placement, he had no eye opening, no vocalization, and weakly localized with his upper extremities. 
TABLE 1

SUMMARY OF PREOPERAT WE IMAGNG, OPERATIYE MANAGEMENT, AND OUTCOME IN PATIENTS WHO UNDERWENT ENDOSCOP K MANAGEMENT OF CVSTICERCAL CVSTS WITHN THE THRD AND LATERAL YENTRICLES ${ }^{\star}$

\begin{tabular}{|c|c|c|c|c|c|c|c|c|}
\hline \multirow[b]{2}{*}{$\begin{array}{l}\text { Case } \\
\text { No. }\end{array}$} & \multirow[b]{2}{*}{$\begin{array}{l}\text { Hydrocep t } \\
\text { alus ( preop) }\end{array}$} & \multirow[b]{2}{*}{$\begin{array}{l}\text { Cyst } \\
\text { Location }\end{array}$} & \multicolumn{5}{|c|}{ End osc opic Waragement } & \multirow[b]{2}{*}{$\begin{array}{l}\text { YP Shunt } \\
\text { Placed (FU) }\end{array}$} \\
\hline & & & $\begin{array}{l}\text { Epert } \\
\text { dymitist }\end{array}$ & $\begin{array}{c}\text { Cyst } \\
\text { Integity }\end{array}$ & 3rd $Y$ & $S P$ & $\begin{array}{l}\text { Retain ed } \\
\text { Cyst(s) }\end{array}$ & \\
\hline 1 & $\begin{array}{l}\text { dilation of lat } \& \\
\text { 3rd wentricles }\end{array}$ & rt occiphorn & mild & tear & yes & no & no & no $(4 \mathrm{mos})$ \\
\hline 2 & $\begin{array}{l}\text { dilation of lat \& } \\
\text { 3rd wentricles }\end{array}$ & It occip horn $\ddagger$ & mild & $\begin{array}{l}\text { not re- } \\
\text { trieved }\end{array}$ & yes & no & yes & no $(6 \mathrm{mos})$ \\
\hline 3 & $\begin{array}{l}\text { dilation of lat } \& \\
\text { 3rd wentricles }\end{array}$ & $\begin{array}{l}\text { rt } \& \text { It occip } \\
\text { horns }\end{array}$ & none & tear & yes & yes & no & no (2 mos) \\
\hline 4 & $\begin{array}{l}\text { dilation of lat wen- } \\
\text { tricles It }>\text { rt }\end{array}$ & $\begin{array}{l}\text { It occip horn on } \\
\text { im aging, near } \\
\text { foramen of } \\
\text { monro at op }\end{array}$ & none & tear & no & no & no & no (2 wks) \\
\hline 5 & $\begin{array}{l}\text { dilation of rt lat } \\
\text { ventride }\end{array}$ & rt occip horn & $\begin{array}{l}\text { Severe at } \\
\text { rt fora- } \\
\text { men of } \\
\text { monro }\end{array}$ & in tact & no & yes & no & no $(6 \mathrm{mos})$ \\
\hline 6 & $\begin{array}{l}\text { dilation of lat } \& \\
\text { 3rd ventricles }\end{array}$ & $\begin{array}{l}\text { posterior 3rd } \\
\text { wentride }\end{array}$ & moderate & tear & no & no & no & no $(1 \mathrm{mo})$ \\
\hline 7 & $\begin{array}{l}\text { dilation of rt lat } \\
\text { ventride }\end{array}$ & $\begin{array}{l}\text { roof of anterior } \\
\text { 3rd wentricle }\end{array}$ & none & tear & no & yes & no & no (4 mos) \\
\hline 8 & $\begin{array}{c}\text { dilation of all } \\
\text { wentrides }\end{array}$ & It ocsip horn & none & leak & no & no & no & $\begin{array}{l}\text { yes, at time } \\
\text { of op }\end{array}$ \\
\hline 9 & $\begin{array}{l}\text { dilation of all } \\
\text { ventrides }\end{array}$ & $\begin{array}{l}\text { multiple in rt } \\
\text { and It lat } \& 3 \text { rd } \\
\text { ventrides }\end{array}$ & focal & tear & no & yes & $\begin{array}{l}\text { multi- } \\
\text { ple }\end{array}$ & yes, preop \\
\hline 10 & $\begin{array}{l}\text { dilation of lat } \& \\
\text { 3rd ventricles }\end{array}$ & $\begin{array}{l}\text { posterior 3rd } \\
\text { wentrides }\end{array}$ & none & tear & no & no & no & $\begin{array}{l}\text { yes, at } 10 \\
\text { days post- } \\
\text { op }\end{array}$ \\
\hline
\end{tabular}

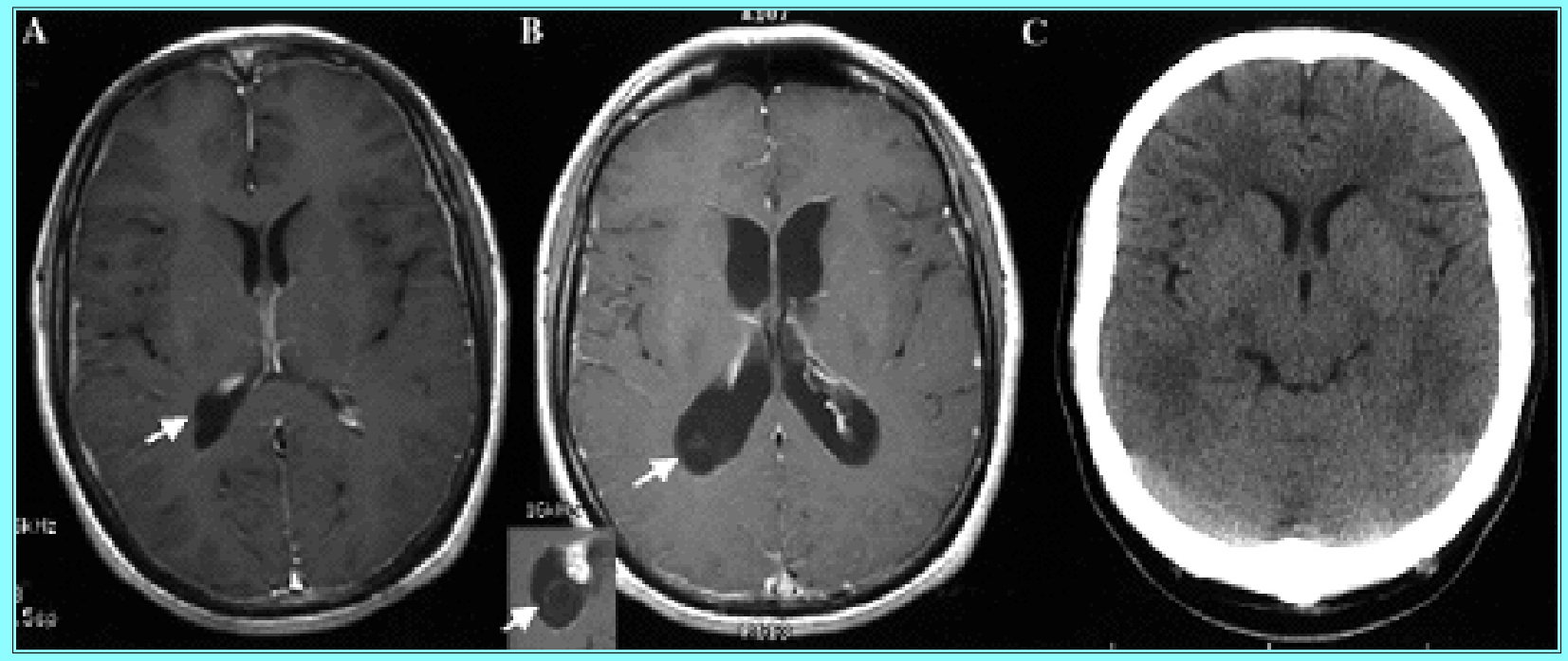

Fig. 1. Imaging studies demonstrating aqueductal stenosis and intraventricular cyst. A: Contrast-enhanced $\mathrm{T}_{1}$-weighted $\mathrm{MR}$ image demonstrating a cyst in the right atrium (arrow) of the lateral ventricle without hydrocephalus. B: Contrast-enhanced $\mathrm{T}_{1}$-weighted MR 
image obtained 3 years later showing the cyst in the same position (arrow) but now also demonstrating hydrocephalus (pattern consistent with aqueductal stenosis; not shown). Inset: Next lower MR imaging plane better demonstrating cyst in the atrium. C: Noncontrast CT scan obtained 4 months after endoscopic removal of the cyst and third ventriculostomy. The patient was asymptomatic, and the hydrocephalus resolved without the need for placing a shunt.

\section{Prior Treatment}

The patient in Case 9 underwent placement of a CSF shunt prior to the diagnosis of intraventricular cysticercosis. A single patient (Case 10), who previously underwent anthelmintic therapy, presented to an outside hospital with a seizure and was found to have multiple parenchymal cysts and hydrocephalus. He was treated with albendazole only and was hospitalized 1 month later with increasing lethargy secondary to worsening hydrocephalus.

\section{Neuroimaging Findings}

Eight of the 10 patients underwent magnetic resonance (MR) imaging preoperatively. In one patient (Case 2; Table 1), the MR imaging study did not reveal a definite intraventricular cyst but instead demonstrated an area of enhancement in the ependyma of the left occipital horn. This area was confirmed endoscopically to be associated with an intraventricular cyst. In the patient in Case 9 three MR imaging studies performed prior to the placement of a shunt demonstrated communicating hydrocephalus without evidence of intraventricular cysts (Fig. 2A). In this same patient, subsequent MR images obtained following several shunt revision procedures clearly demonstrated intraventricular cysts (Fig. 2B).

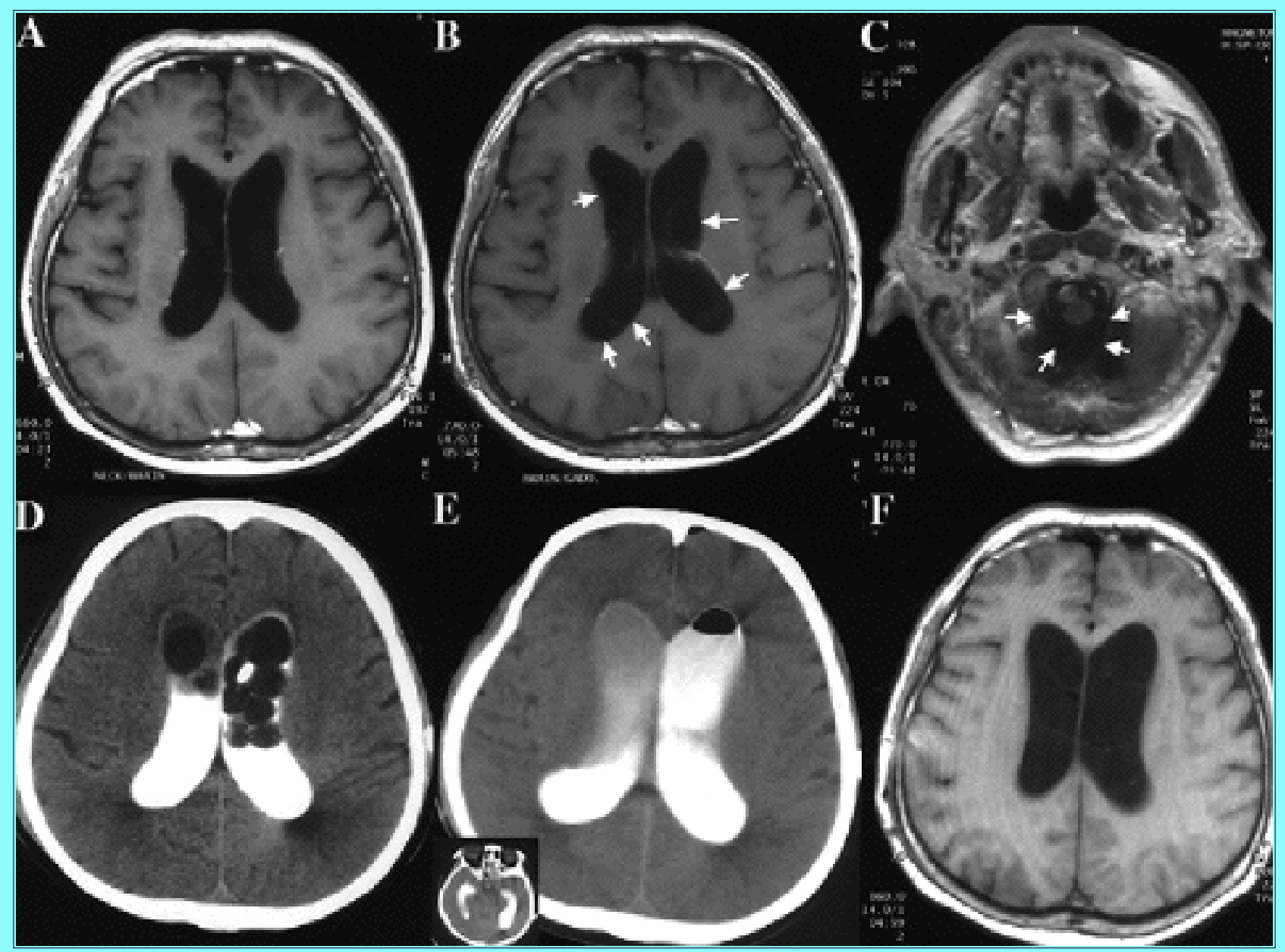


Fig. 2. Imaging studies demonstrating shunt-induced infestation of intraventricular cysts. A: Contrast-enhanced $\mathrm{T}_{1}$-weighted MR image demonstrating communicating hydrocephalus without evidence of intraventricular cysts. A VA shunt was subsequently placed, which required multiple revisions due to obstruction. $\mathrm{B}$ and $\mathrm{C}$ : Contrast-enhanced $\mathrm{T}_{1}$-weighted $\mathrm{MR}$ images obtained after fourth shunt revision revealing multiple intraventricular cysts (arrows) not present on earlier study. Imaging of the upper cervical spine also confirmed multiple subarachnoid cysts (arrows). D: Corresponding contrast-enhanced CT ventriculogram to MR imaging confirming multiple cysts within the ventricles. All of the third and lateral ventricular cysts were removed endoscopically. E: Postoperative contrast-enhanced CT ventriculogram obtained 4 days after an endoscopic procedure demonstrated no cysts within the third and lateral ventricles (including temporal horns; see inset). A shunt was placed again. F: Two months later this shunt became obstructed, and the $\mathrm{T}_{1}$-weighted MR image demonstrated large cysts densely packed once again within the ventricular system.

Of the remaining six patients in whom preoperative MR imaging studies had been obtained, a discernible intraventricular cyst was revealed on contrast-enhanced $\mathrm{T}_{1}$-weighted imaging (see Figs. 1 and 3 ). Three radiological reports included descriptions of probable cysts, which were subsequently not found endoscopically and probably represented CSF motion artifact. Three patients underwent intraventricular contrast-enhanced computerized tomography (CT) studies, all of which clearly demonstrated cysts.

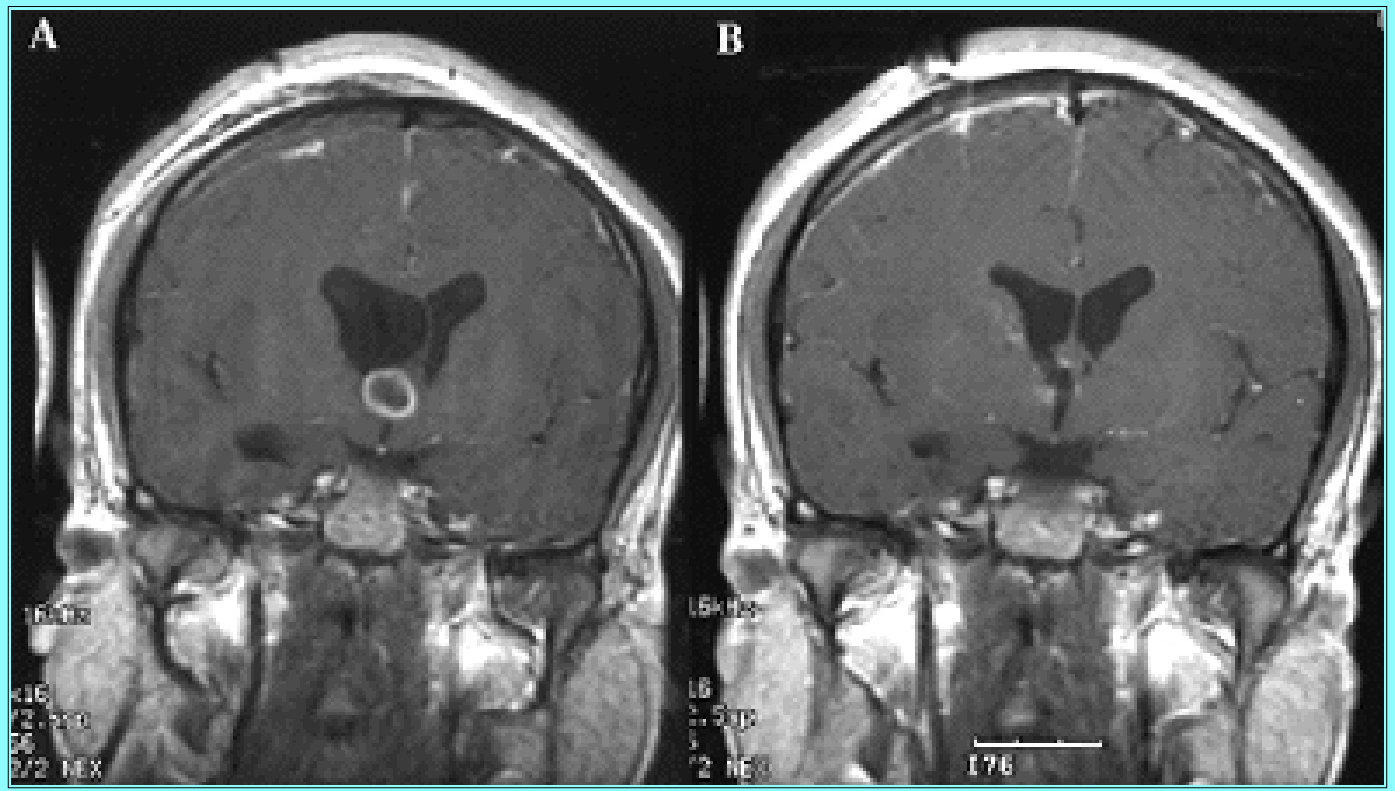

Fig. 3. Anterior third ventricle cyst. A: A $T_{1}$-weighted coronal MR image demonstrating a ring enhancing cyst in the in the roof of the anterior third ventricle. The cyst is causing hydrocephalus with predominant dilation of the right lateral ventricle. B: The lesion was resected using a transcortical, transventricular endoscopic technique. The postoperative contrast-enhanced $\mathrm{T}_{1}$-weighted MR image demonstrates complete excision of the lesion and resolution of the hydrocephalus.

Ventricular dilation was seen on all studies (Table 1). In five cases, the lateral and third ventricles were dilated, whereas the fourth ventricle was normal in size--a pattern interpreted to be consistent with aqueduct obstruction. Obstruction of the foramen of Monro was inferred in three cases based on unilateral dilation of a lateral ventricle (Figs. 3 and 4). 


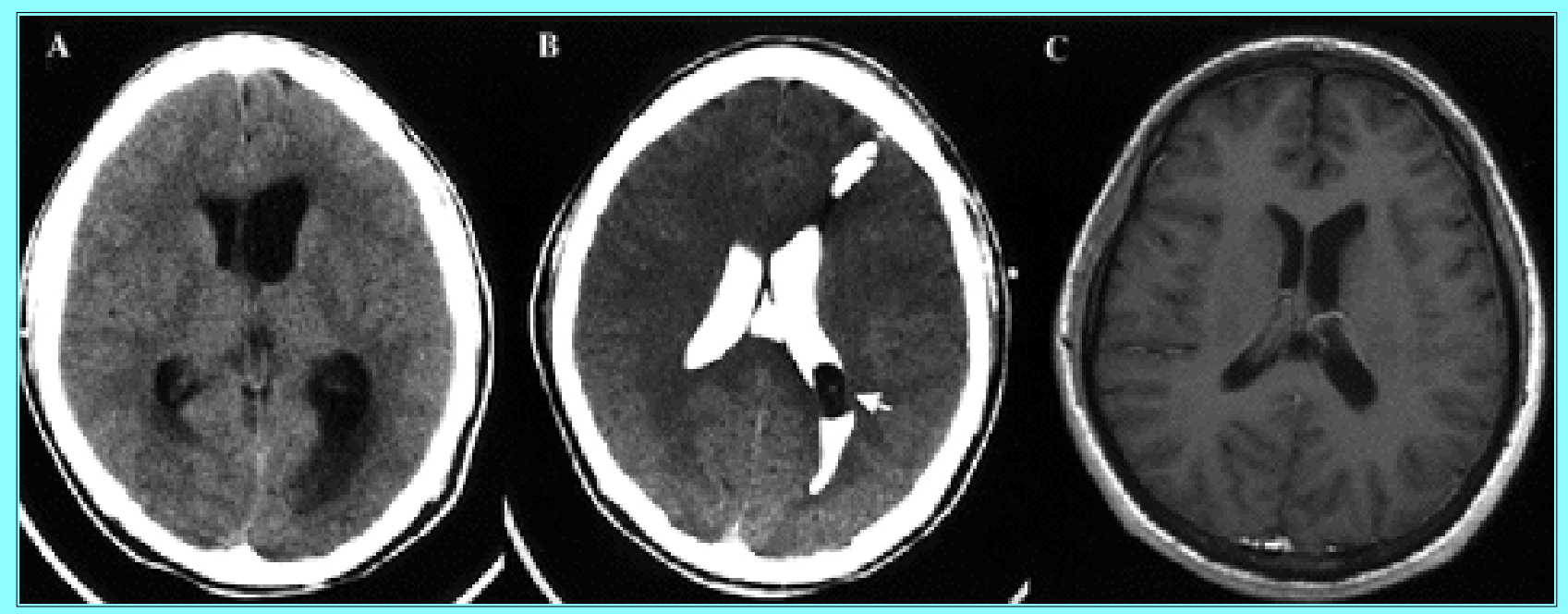

Fig. 4. Image studies demonstrating a lateral ventricle cyst causing ball-valve unilateral hydrocephalus. A: Noncontrast CT scan revealing unilateral dilation of the left lateral ventricle. B: Following ventriculostomy placement, intraventricular contrast was administered. The CT scan demonstrates a single cyst (arrow) located at the atrium of the left lateral ventricle. C: At surgery, the cyst was found at the foramen of Monro and removed endoscopically. The postoperative contrast-enhanced $\mathrm{T}_{1}$-weighted $\mathrm{MR}$ image revealed near normalization of the ventricle size and no evidence of retained intraventricular cysts.

Despite these "obstructive" patterns, cysts located in the presumed obstruction site were identified in only four cases (Cases 6, 7, 9, and10). As shown in Table 1, six patients were found (directly or indirectly) to harbor cysts in the dependent occipital horn of the lateral ventricle. In view of the rapid clinical deterioration with acute obstructive hydrocephalus on the initial CT scan, it was inferred that in at least two patients (Cases 4 and 5) the cyst in the occipital horn had intermittently obstructed the ipsilateral foramen of Monro and then retreated back to the occipital horn (Fig. 4).

Included in this analysis is a patient (Case 7; see Illustrative Cases) in whom obstructive hydrocephalus was secondary to a cysticercal cyst situated in the anterior third ventricle. After close inspection of the MR imaging studies, it appeared that the cyst was most likely in the velum interpositum (Fig. 3). The cyst in this case was approached and successfully resected endoscopically and, therefore, thought to be pertinent to this endoscopic series.

\section{Description of Endoscopic Technique}

Preoperative Management. Patients who presented with symptoms of acute hydrocephalus underwent placement of a frontal ventriculostomy (four patients). Perioperative prophylactic antibiotic drugs and intravenous dexamethasone were given to all patients.

Endoscopic Instrumentation and Approach. A number of different endoscopes were used in these operations. In most procedures, a greater degree of endoscopic maneuverability was desired, and therefore, a flexible, steerable instrument was used (either the Neuronavigational 4.6-mm steerable [Neuronavigational Corp., Costa Mesa, CA] or 4-mm steerable, flexible neuroendoscope. Three procedures were performed using a rigid lens endoscope (either the Codman Gaab neuroendoscope system or a Storz $2.7-\mathrm{mm}, 30^{\circ}$ rigid-lens viewing scope (Karl Storz GmbH and Co., Tuttingen, Germany). 
In each case, the patient was placed in the supine position, with no rotation of the head so as to maintain vertical orientation. The positioning, preparation, and draping of the patient were planned as if a CSF shunt were to be placed. Frontal, precoronal burr-hole approaches, either left or right, were used in all cases. In the patients in whom the flexible steerable endoscopes were used, a No. 9 French blunt-tipped peel-away catheter was introduced into the ventricular system. In one case, a two-portal technique was utilized (Case 9). Whenever possible, the endoscope was set up and secured to the accompanying endoscope holder that was attached to a Bookwalter mount. Either Plasmalyte or lactated Ringer's solution was used for gravity-fed irrigation.

General Technique for Cyst Removal. Once the cyst was identified with the endoscope, an assessment was made concerning whether the cyst could be safely removed. If the cyst was not freely floating in the ventricle, the continuous irrigation and the mechanical presence of the endoscope separated the cyst from the ependymal wall and choroid plexus in nearly all cases. Once it was confirmed that the cyst was not inseparably adherent to an ependymal surface, the transendoscopic grasping instrument was advanced down the working channel of the endoscope. After grasping the cyst wall, the grasping instrument was retracted to the point at which the cyst was approximately $5 \mathrm{~mm}$ from the distal tip of the endoscope. No attempt was made to withdraw the cyst through the working channel of the endoscope because it was too small to accommodate the entire cyst. The anesthesiologist was asked to perform a gentle and sustained Valsalva maneuver (to about $30 \mathrm{~mm} \mathrm{Hg}$ airway pressure) while the endoscope was carefully backed out and withdrawn. The cyst was maintained just beyond the distal end of the endoscope and delivered to the specimen cup. If the cyst wall tore, the fragmented piece was delivered, the grasper reapplied, and the withdrawal technique repeated until the entire cyst was removed. The endoscope was navigated back into the ventricle and additional cysts, if present, were removed using the aforementioned technique. Once all cysts were removed, the ventricular system was inspected a final time, and irrigation was continued until all cloudiness of the ventricular fluid cleared.

In two cases, a previously placed ventriculostomy catheter was used to pressurize slightly the ventricular system while the cyst was being removed through the peel-away cannula. We found this technique to be more effective than the Valsalva maneuver for the removal of large cysts. In two patients ventriculostomy catheters were maintained for 24 hours postoperatively for monitoring purposes.

Third Ventriculostomy. In three of the 10 cases, an endoscopic third ventriculostomy was performed in conjunction with the cyst removal procedure (Table 1). The indications for this procedure included the preoperative diagnosis of hydrocephalus secondary to aqueductal stenosis combined with the endoscopic confirmation that no cyst was occluding the aqueduct on evaluation of the third ventricle. The tuber cinereum was first punctured using the straight end of a vascular guidewire (0.032-inch diameter). The puncture site was chosen as the midline point just posterior to the vascular discoloration imparted by the infundibular recess. A No.3 French Fogarty balloon catheter was then used to expand the perforation, and then the flexible endoscope was navigated into the interpeduncular cistern to confirm the fenestration of the membrane of Lilliequist.

Septum Pellucidotomy. In four of the 10 cases, an endoscopic septum pellucidotomy was performed (Table 1). In three patients, this was undertaken to evaluate the opposite lateral ventricle for the presence of cysts. In one patient (Case 5), the septum pellucidotomy was conducted as a therapeutic procedure to alleviate unilateral hydrocephalus. The perforation, located posterior to the anterior septal vein, was made using a monopolar cautery wire and then mechanically enlarged by the endoscope. 


\section{RESULTS}

\section{Successful Cyst Removal}

In nine of the 10 patients, the ventricular cysts identified on the preoperative imaging study was successfully removed. In one patient (Case 2), the cyst was clearly identified adjacent to the choroid plexus in the posterior aspect of the body of the right lateral ventricle. Because a flexible endoscope was not used, the grasping instrument could not be positioned to capture the cyst. In the patient in Case 9, there were several recurrences of ventricular cyst infestation that were each treated endoscopically (see Illustrative Cases and Fig. 2).

\section{Cyst Leakage and Tear}

A leak of the cyst contents was assumed to occur based on the appearance of a white "smokelike" substance in the CSF that emanated from the cyst when capturing it with the grasping instrument. Leakage of the cyst contents occurred in all but two cases (Cases 2 and 5). The incidence of a visible tear of the cyst wall, on the other hand, was largely a function of cyst size. Cysts less than $15 \mathrm{~mm}$ in diameter generally were removed intact. Six cases were associated with tears in the walls of at least one cyst upon retrieval (Fig. 5). In no patient did endoscopic reinspection reveal residual pieces of extracted cysts within the ventricular system.

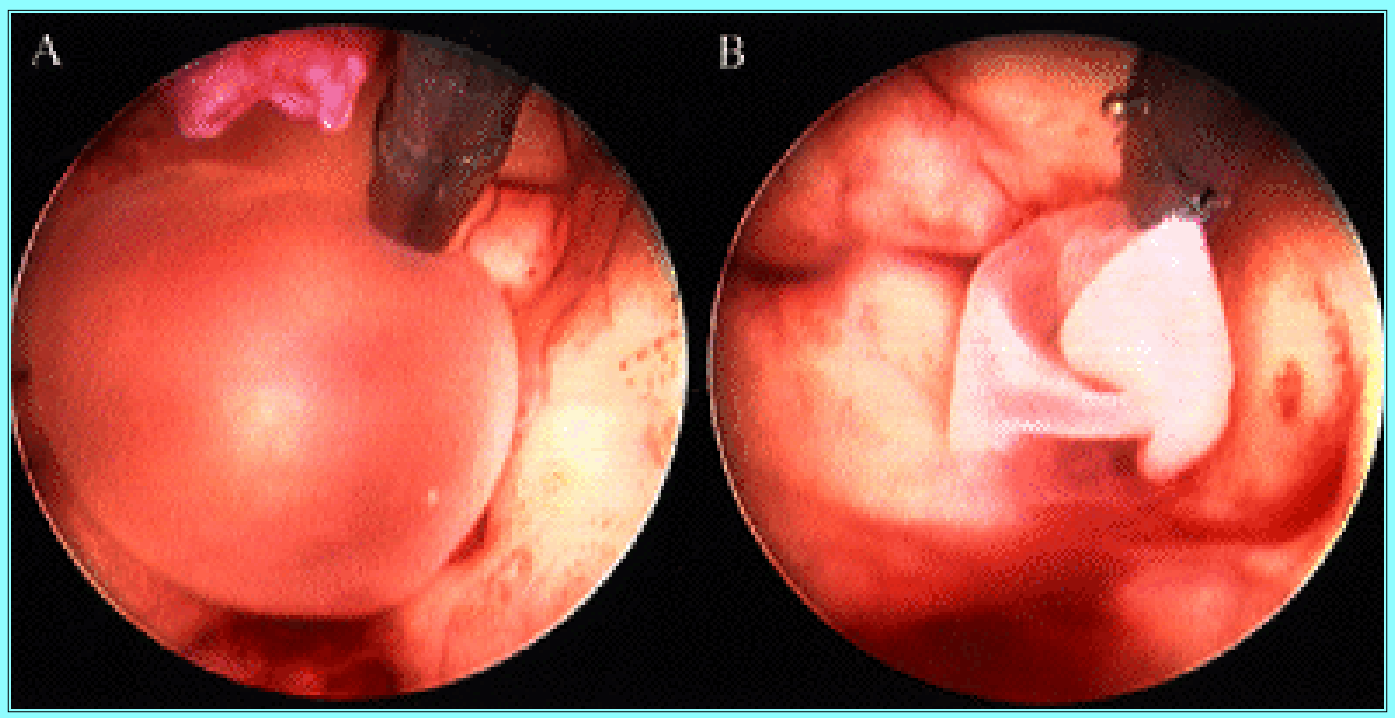

Fig. 5. Endoscopic view of removal of intraventricular cysts. A: Unruptured cysticercal cyst within the lateral ventricle secured by transendoscopic grasper. B: Retrieval of previously ruptured, and now collapsed, cysticercal cyst within the lateral ventricle.

\section{Prevalence and Incidence of Ependymitis}

Based on the endoscopic appearance of the ventricular wall, the ependyma in five of the 10 procedures showed signs of granular ependymitis at the time of operation. In two cases, there was evidence of ependymal enhancement preoperatively (Cases 2 and 9). This occurred more commonly in conjunction with degenerating cysts, which appeared to have a more greenish hue and were sometimes associated with a matrix of a lacy, mucoid material surrounding them. Some cysts were loosely adherent to the ventricular wall, whereas others freely floated in the CSF, often spinning as if weightless in space.

\section{Surgery-Related Complications}


Two patients suffered worsening of their neurological condition following an endoscopic procedure (see Illustrative Cases). For the patient in Case 9, neurological deterioration was not clearly attributable to an injury related to endoscopy. In the second patient (Case 10) a deep venous thrombosis was diagnosed more than 2 weeks after the endoscopic procedure.

\section{Success in Avoiding a CSF Shunt}

Seven of the 10 patients did not require CSF shunt placement. In two patients (Cases 6 and 7) removal of the obstructing cyst at the aqueduct or the foramen of Monro proved to be sufficient to relieve the hydrocephalus. In three other patients (Cases 1-3) a third ventriculostomy, in conjunction with removal of a cyst(s) located in the occipital horn, alleviated the hydrocephalus. In one patient (Case 5) in whom the right lateral ventricle was unilaterally dilated, a septum pellucidotomy, in conjunction with removal of a cyst located in the right occipital horn, was effective. Finally, for the patient in Case 4, it is assumed that the cyst removed from the left occipital horn was responsible for causing intermittent obstructive hydrocephalus. Once removed, no further episodes of hydrocephalus occurred (Fig. 4).

For the seven patients in whom CSF shunt placement was avoided, the mean follow-up period was 13.4 weeks (range 2-24 weeks). Four of these seven patients were lost to follow up (Cases 2, 4, 6, and 7), and the remaining three continue to be seen regularly and screened for the delayed appearance of hydrocephalus.

Three of the 10 patients required a CSF shunt. One patient (Case 9) underwent shunt placement prior to being diagnosed as having intraventricular cysts. Endoscopic management with attempted removal of subsequently discovered intraventricular cysts did not free him from his dependency on the shunt. One patient (Case 8) presented with communicating hydrocephalus and underwent the placement of a ventriculoperitoneal shunt at the time of the endoscopic exploration and removal of an occipital cyst. In this case, the cyst removal was performed to lessen the risk of cyst degeneration-related morbidity. At 3 month follow-up evaluation, he had not required revision of the shunt nor had he experienced any problems related to cysticercosis-related inflammation. In the one patient who received prior albendazole treatment (Case 10), the removal of a posterior third ventricular cyst did not result in a reduction of the ventricular size. Although the patients' neurological status improved, placement of a ventriculoperitoneal shunt 10 days later was performed by another neurosurgeon.

\section{Sources of Supplies and Equipment}

The Plasmalyte used in the anti-gravity irrigation was aquired from Baxter (Deerfield, IL). The cautery wire (model ME-2), the steerable, flexible neuroendoscope, and the Codman Gaab neuroendoscope system were obtained from Codman and Shurtleff, Inc. (Randolph, MA). The 4.6-mm steerable neuroendoscope was obtained from Neuronavigational Corp. (Costa Mesa, CA). We acquired the rigid-lens viewing scope from Karl Storz GmbH and Co. (Tuttingen, Germany).

\section{ILLUSTRATIVE CASES}

Two patients were sufficiently unique in terms of the presentation, management, and complications that a more detailed case description is given. The first was a patient who harbored a cysticercal cyst in the roof of the third ventricle that was removed using a two-portal endoscopic technique. The second case was that of a patient with an iatrogenic recurring cysticercal infestation of the ventricular system. These cases illustrate the complex and difficult problem of managing this disorder. 


\section{Case 7}

Cyst in the Roof of the Third Ventricle. This 24-year-old Mexican man presented with a 1-month history of a syncopal episode and 1-week history of progressive headaches and nausea prior to admission. His neurological status was unremarkable other than mild papilledema. The preoperative CT and MR imaging studies revealed a cystic lesion in the anterior third ventricle that obstructed the foramina of Monro bilaterally and caused obstructive hydrocephalus. On the imaging studies, the coronal views suggested that the lesion appeared to be in the velum interpositum (Fig. 3). A ventriculostomy was placed and dexamethasone begun. Via a right frontal, precoronal burr hole situated along the midpupillary line, a $30^{\circ}$ rigid lens viewing endoscope was advanced into the lateral ventricle. The right foramen of Monro was found to be completely occluded by a lesion enveloped in a thin veil of arachnoid. A second burr hole was made $1 \mathrm{~cm}$ lateral to the first, and a No. 9 French peel-away catheter was inserted into the right lateral ventricle. This was utilized as a "working channel," allowing the introduction and manipulation of several standard microneurosurgical instruments. The cyst wall was coagulated using a Bovie monopolar tip, and the thick-walled cyst was removed in a piecemeal fashion by using Decker forceps.

\section{Click here to view Video 1.}

Video 1. Two portal technique for removal of cysticercal cyst in the roof of third ventricle. Endoscopic view of foramen of Monro from right lateral ventricle. The cyst completely fills the foramen. The choroid plexus is seen in the lower part of the field. Through a second port (No. 9 French peel-away catheter), a Decker forceps is used to expose the degenerated cyst. [break] The cyst is then dissected and subtotally withdrawn. [break] Finally, the cyst is removed, causing minimal hemorrhage. The endoscope can then be easily advanced into the third ventricle (not shown).

Following the complete removal of the lesion, the endoscope was advanced through the now patent foramen of Monro, and the floor of the third ventricle was visualized. Results of histological examination confirmed a cysticercal cyst wall with necrotic larva and a small amount of surrounding gliotic brain parenchyma. Postoperatively, the patient had a mild, transient pronator drift of the left arm. His short-term memory function was intact. He was discharged home without headache, and he did not require a CSF shunt at 4-month follow-up review.

\section{Case 9}

Shunt-Induced Recurrent Infestation of Intraventricular Cysticercosis. This 67-year-old Korean man presented in December 1995 with a 3-week history of headache, nausea, and gait instability. Although MR imaging revealed mild communicating hydrocephalus with no focal abnormalities, the tentative diagnosis of temporal arteritis was made, and he was discharged home. Two weeks later, he was readmitted with worsening symptoms, and a repeated MR image (with intravenous contrast) was again interpreted to reveal communicating hydrocephalus (Fig. 2A). He underwent a ventriculoatrial (VA) shunt placement that required three subsequent shunt revisions within 1 month. At the third shunt revision, a cysticercal cyst was pulled out when the ventricular catheter was withdrawn. Postoperative MR imaging and CT ventriculography revealed multiple ventricular and cisternal cysts (Fig. 2B-D).

The first endoscopic exploration was performed via bilateral, precoronal, frontal burr holes. By using 
both flexible and rigid-lens endoscopes, 25 cysts were removed from both lateral ventricles and the third ventricle.

\section{Click here to view Video 2.}

Video 2. Endoscopic removal of cysticercal cyst from lateral ventricle. From the right frontal approach, a cyst in the cella media of the ipsilateral ventricle is captured and removed. Note that the cyst wall ruptures when trying to draw the cyst through the endoscopic cannula. Despite this tear, the entire cyst is successfully removed.

Five cysts definitely tore during this procedure (Fig. 5). Results of the pathological report confirmed racemose cysticercal cysts. Postoperatively, the patient was more confused and only intermittently followed commands. Multiple CSF analyses were not suggestive of ventriculitis of any sort. A repeated CT ventriculogram confirmed the removal of all cysts within the lateral and third ventricles (Fig. 2E), and therefore, he underwent a replacement of the VA shunt on approximately 1 month after initial endoscopic exploration. One day postoperative CT scanning demonstrated enlargement of the ventricular system, and the following day he underwent VA shunt revision with endoscopic exploration. By using the flexible endoscope, eight more cysts were found and removed from the left lateral and third ventricles. The shunt was revised, now with bilateral ventricular catheters. His neurological status slightly improved, although he remained disoriented despite normal findings on CSF examination. He was discharged from the hospital several days later but returned after 1 week with increasing lethargy. An MR imaging study demonstrated recurrence of hydrocephalus, but now numerous new cysts were seen in the third and lateral ventricles (Fig. 2F). In a third endoscopic procedure, the flexible endoscope was used to remove 35 more cysts from the ventricles.

Because the patient continued to deteriorate neurologically despite maintenance of a normal ventricular size, he underwent a suboccipital craniotomy with removal of 78 cysts from the posterior fossa cisterns, the fourth ventricle, and the upper cervical canal region (Fig. 6). This was accomplished both using the operating room microscope and the flexible endoscope for exploration of the cerebellopontine cisterns. A final VA shunt revision was performed approximately 3 weeks later, and, somnolent and no longer following commands, he was transferred to a subacute care facility. 


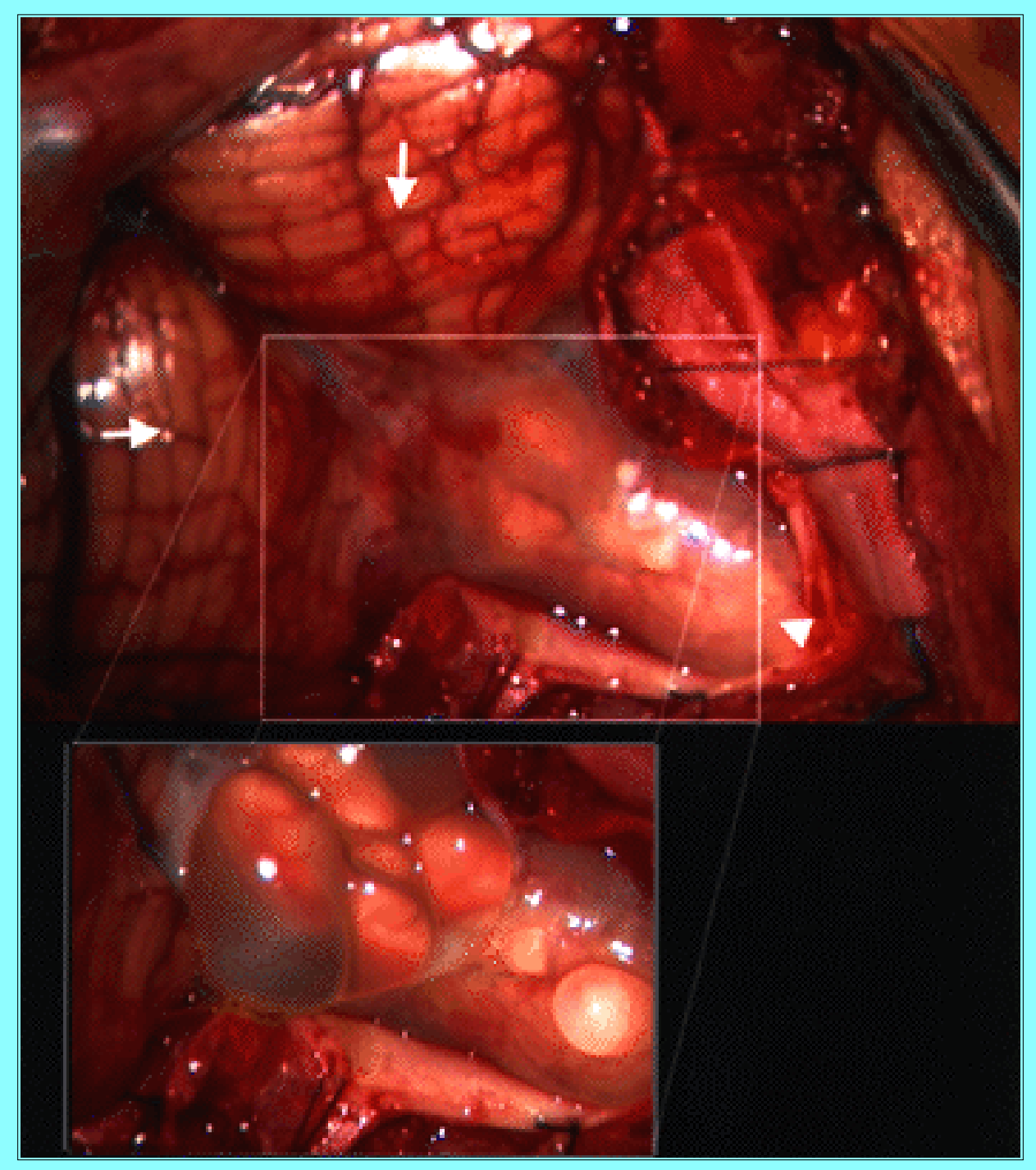

Fig. 6. Intraoperative photographs demonstrating subarachnoid cysticercal cyst involvement as a source of ventricular cysts. Upper: Suboccipital craniectomy and C-1 laminectomy demonstrating the foramen magnum. Arrows indicate the cerebellar hemispheres, and the arrowhead indicates the cervical spine. Lower: Following the opening of the arachnoid, multiple racemose cysticercal cysts are apparent. It was presumed that cysts from this location were drawn up to the third and lateral ventricles by a VA shunt. A total of 78 cysts were removed in this operation.

This was an extraordinary case in which it was believed that the VA shunt had caused a retrograde movement of cysts from the posterior fossa to the third and lateral ventricles on at least two occasions. This, in turn, led to multiple shunt obstructions. Although the cause of his neurological deterioration was not definitively determined, it was thought to be secondary to repeated bouts of hydrocephalus and not due to chemical meningitis or ventriculitis.

\section{DISCUSSION}

Our experience demonstrates that many patients with cysticercosis involving the lateral and third ventricle can be managed principally using neuroendoscopic techniques. The endoscopic management of intraventricular cysticercosis has been advocated previously, $[9,10,14,22]$ although the actual descriptions of the technique used, including results, have been only anecdotal. Apuzzo, et al.,[1] in 1984, described the use of a $6.8-\mathrm{mm}$-rod lens endoscope system for the removal of a lateral ventricular cyst. They used 
stereotactic guidance attached to a frame-mounted system and noted that the cyst ruptured during excision. In 1995, Neal[27] reported the use of a prototype rigid endoscope for removal of a cyst located in the posterior third ventricle. Through the working channel of the rigid endoscope, a No. 7.2 French ureteroscope was introduced and used to pull the cyst away from the aqueduct by using gentle suction. The cyst did not rupture and no postoperative complications were reported.

The endoscopic removal of intraventricular cysts has also been briefly described in several textbooks, including two edited by authors of this paper.[5,6] In a textbook published in 1996, Loyo-Varela et al.,[23] proposed that in patients with cysts in the lateral/third and fourth ventricles, a frontal endoscopic approach to the lateral ventricle could be used simultaneously while the patient was undergoing a suboccipital craniectomy for the fourth ventricular cyst. Interestingly, they proposed forcing the cyst through the cerebral aqueduct with "downward pressure" and, therefore, delivering the cyst into the open surgical field in the posterior fossa. If the cyst could not be forced into the fourth ventricle, they then proposed direct removal via the endoscope. Specific results and complications associated with this management plan were not given.

\section{The Rationale for Primary Surgical Excision of Intraventricular Cysts}

Because most patients with intraventricular cysts present with hydrocephalus, the primary goal is to alleviate the associated intracranial hypertension. Several authors have advocated that this should be accomplished by placing a CSF shunt as the initial procedure. $[4,8,26]$ This practice has been primarily based on several considerations. First, because cysticercosis is a chronic inflammatory disease, there can be both a communicating and noncommunicating etiology of the hydrocephalus; therefore, some patients will require CSF shunt placement even if the obstructive component is alleviated. Second, an open craniotomy for excision of a cyst is considered to be more complicated, produce more trauma to brain tissue, and be a higher-risk procedure relative to a CSF shunt. Third, it is considered by some that an open craniotomy can be avoided in selected patients by treating the patient with albendazole instead. Although these considerations have some validity, there are also compelling reasons to remove the cyst as the primary procedure.

CSF Shunts are Prone to Obstruction with Neurocysticercosis. The postoperative complications associated with a CSF shunt, for all causes of hydrocephalus, are not insignificant. By 6 years, $50 \%$ of patients in whom CSF shunts have been placed require at least one revision.[32] When associated with neurocysticercosis, the shunt-related morbidity rate is even higher. In one study of neurocysticercosis, 46 (82\%) of 56 patients undergoing CSF shunt placement required reoperation due to malfunction of the shunt.[8] There are no reported estimates of the shunt survival rate in patients who harbor intraventricular cysts; however, our experience (as illustrated by Case 9) confirms that of others:[33] the cyst itself can get sucked into the ventricular catheter, thereby obstructing it. Moreover, it appeared that a CSF shunt could actually draw cysts from the posterior fossa into the supratentorial ventricular system. Our endoscopic exploration of the ventricles also revealed, in many cases, the existence of a lacy, mucoid material surrounding degenerating cysts. We suspect that this material, as well as other inflammation-related debris, could account for some cases of shunt obstruction in patients undergoing a CSF shunt placement without cyst removal.

CSF Shunts do not Obviate Risks Related to Cyst Degeneration. Because a CSF diversionary procedure leaves the intraventricular cyst in situ, the death of the cyst can provoke ependymitis and arachnoiditis[7,13,21,29] and, therefore, worsen the prognosis significantly.[16,35] In addition, a 
degenerating cyst can dramatically increase in size, causing a local mass effect[7,8] and/or a compartmentalized hydrocephalus.

Primary Medical Treatment has Associated Risks. How should a patient who harbors intraventricular cysts but who does not have hydrocephalus be managed? Because the natural course of this disease is variable, there will always be differing opinions with regard to this question. Del Brutto and Sotelo[12] have reported a patient in whom a large lateral ventricular cyst completely disappeared 3 months after undergoing albendazole therapy; they therefore proposed that anthelmintic therapy should be considered as the first-line treatment option. The primary medical treatment of neurocysticercosis has not gained universal acceptance because of the lack of irrefutable scientific evidence to support its effectiveness. This is especially true for the intraventricular form of the disease, for which only anecdotal reports exist. The most persuasive argument against lone anthelmintic treatment is that until the cyst "disappears," the patient is still at risk for life-threatening complications. As mentioned previously, intraventricular cysts can cause sudden death secondary to obstructive hydrocephalus. As an equally important consideration, anthelmintic treatment accelerates the inflammatory process associated with cyst degeneration and can thereby lead to ependymitis and arachnoiditis complications despite the prophylactic use of corticosteroidal drugs.[4] Our series includes only one patient who was treated with albendazole (Case 10). It is not known whether we could have avoided placing a CSF shunt in this patient had he not undergone anthelmintic therapy prior to removal of the posterior third ventricular cyst.

\section{Endoscopy Compared with Open Craniotomy Procedure to Remove Intraventricular Cysticercal Cysts}

The transcallosal and transcortical-transventricular approaches to the lateral and third ventricle via an open craniotomy have been the standard procedures for the removal of intraventricular cysts.[1,8,17,20,24,25,36] These procedures can be technically demanding and are not without the risk of major complications. The transcallosal approach, with transection of the corpus callosum, can be associated with significant transient memory loss[2,18] in addition to occasional serious complications including hemiparesis, mutism, and aphasia.[3] Even frontal craniotomies via a transcortical approach to lateral ventricle cysticercal cysts can be associated with major deficits, including hemiplegia, homonymous hemianospia, and dementia.[26] Although the use of neuroendoscopy is not without risks, the following are potential and real advantages of this technique over the standard craniotomy approaches.

Intraventricular Cysts are Frequently Mobile. Our experience clearly demonstrates that cysts can migrate prior to and during a resection procedure. Because most patients are placed in the supine position, freely mobile lateral ventricular cysts were frequently found near the occipital horn. The decision of which open craniotomy approach to use involves weighing the neurological deficits against impractical open surgical reaches. Moreover, because a cyst can shift with head movement, there is no guarantee in any given open surgical approach that the cyst will remain be in the desired location once the ventricle is opened.

For planning an endoscopic approach, the Codman flexible endoscope via a frontal approach was best suited to retrieve cysts from the occipital horn of the lateral ventricle. Although a rigid endoscope can visualize this area from a far-frontal burr hole approach, the curvature of the lateral ventricle may prevent the grasper from gaining access to the cyst.

Endoscopy Provides Easier Access to Lateral Ventricles and Third Ventricle. As illustrated by the patient in Case 3, we were able to use endoscopy to remove cysts via both occipital horns from a right 
frontal burr hole. Here the flexible and steerable capabilities of the Codman endoscope were ideally suited for this situation. Approaching a similar case of bilateral ventricular involvement by performing open microsurgical techniques would require either bilateral craniotomies or an extensive midline approach.

The open microsurgical approaches to the posterior third ventricle are technically demanding, require a lengthy operative time, and are not without significant risk. However, an endoscope navigated through the foramen of Monro arrives at the same location in a matter of minutes, and manipulation of the fornix is not necessary.

In addition to being capable of easily removing cysts from the third and both lateral ventricles, the endoscopic access also provides the ability to alleviate effectively selected cases of obstructive hydrocephalus. Our success with three of three third ventriculostomies was in line with the published high response rate in adult patients with acquired aqueductal stenosis.[19] It must be acknowledged, however, that the follow-up period in our cases was relatively short, and therefore the long-term success is still uncertain. Additionally, it is highly unlikely procedures such as a third ventriculostomy and septum pellucidotomy would be of benefit as the primary treatment of patients with hydrocephalus complicated by a significant degree of inflammatory arachnoiditis.

Cyst Rupture Does not Appear to be a Significant Problem. A not unexpected consequence of trying to pull large cysts through a No. 14 French peel-away catheter was tearing of the cyst wall. This occurred in $70 \%$ of the procedures. We chose to use a transendoscopic grasper instrument because it was readily available and offered a secure hold of the cyst. Except possibly for the patient in Case 9, we did not find any definitive evidence that cyst rupture poses as significant a risk as warned by others. [25] We were careful to flush the ventricular system of cloudy CSF prior to closure. This along with the perioperative administration of corticosteriods likely accounted for the absence of postoperative ventriculitis in our series.

\section{Even Difficult Cases can be Safely and Effectively Treated Endoscopically. Third ventricular} cysticercal cysts that mimic colloid cysts have been reported and approached via a standard transcallosal craniotomy.[10] As demonstrated in in the patient in Case 7, these lesions can be safely removed endoscopically as well. Although we utilized a two-portal technique, this cyst could have been removed through a single port by using a rigid-lens endoscope system with a working channel had one been available.

Endoscopic Cases Must be Carefully Selected. Patients in whom significant ependymal enhancement is demonstrated on MR imaging have not been effectively managed using open craniotomy techniques[16,35] and therefore are unlikely to benefit from an endoscopic procedure. In these cases the cyst can be densely adherent to the ependyma and/or the choroid plexus, thereby making removal either unsatisfactory or dangerous. As proposed by others, [34] these cases should undergo CSF shunt placement as the primary procedure, perhaps using a specialized shunt system.

An additional advantage of the "burr-hole" approach used in endoscopy is that if it becomes apparent intraoperatively that an endoscopic procedure will not alleviate the hydrocephalus, it is easy to use the existing incision for the placement of a CSF shunt, as evidenced by the patient in Case 8 .

\section{CONCLUSIONS}

Our experience demonstrates that the primary endoscopic removal of intraventricular cysticercal cysts is 
an effective, safe treatment. In seven of 10 patients presenting with hydrocephalus, placement of a CSF diversionary shunt was avoided. Endoscopy allows easy access to both lateral ventricles and the third ventricle via a single burr-hole approach. Ancillary procedures, such as a third ventriculostomy and/or septum pellucidotomy, are also easily performed and can be quite effective. Although the Codman flexible neuroendoscope is the most versatile instrument for this purpose, selected cases can be adequately treated using rigid-lens systems. Because our series includes only 10 patients, a larger multicenter trial should be conducted in a randomized fashion to compare the primary treatment of a CSF shunt and endoscopy, with and without anthelmintic treatment.

\section{Disclosure}

The authors have no financial interest in the instrumentation or equipment listed in the methodology.

\section{Acknowledgments}

The authors would like thank Jinx Fogley and Lucia Miller for their assistance in preparing this manuscript.

\section{References}

1. Apuzzo MLJ, Dobkin WR, Zee CS, et al: Surgical considerations in treatment of intraventricular cysticercosis. An analysis of 45 cases. J Neurosurg 60:400-407, 1984

2. Apuzzo MLJ, Giannotta SL: Transcallosal interfornicial approach, in Apuzzo MLJ (ed): Surgery of the Third Ventricle. Baltimore: Williams \& Williams, 1987, pp 354-380

3. Apuzzo MLJ, Litofsky NS: Surgery in and around the anterior third ventricle, in Apuzzo MLJ (ed): Brain Surgery. Complication Avoidance and Management. New York: Churchill Livingstone, 1993, pp 541-579

4. Bandres JC, White AC Jr, Samo T, et al: Extraparenchymal neurocysticercosis: report of five cases and review of management. Clin Infect Dis 15:799-811, 1992

5. Bergsneider M: Transendoscopic instrumentation and techniques, in King WA, Frazee JG, De Salles AAF (eds): Endoscopy of the Central and Peripheral Nervous System. New York: Thieme, 1997, pp $16-22$

6. Bergsneider M, Frazee JG: Ventricular endoscopy, in De Salles AF, Lufkin RB (eds): Minimally Invasive Surgery of the Brain. New York: Thieme, 1997, pp 254-267

7. Colli BO, Martelli N, Assirati JA Jr, et al: Cysticercosis of the central nervous system. I. Surgical treatment of cerebral cysticercosis: a 23 years experience in the Hospital das Clínicas of Ribeirão Preto Medical School. Arq Neuropsiquiatria 52:166-186, 1994

8. Colli BO, Martelli N, Assirati JA Jr, et al: Results of surgical treatment of neurocysticercosis in 69 cases. J Neurosurg 65:309-315, 1986

9. Couldwell WT, Apuzzo MLJ: Management of cysticercosis cerebri. Contemp Neurosurg 19:1-6, 1989

10. Couldwell WT, Chandrasoma P, Apuzzo MLJ, et al: Third ventricular cysticercal cyst mimicking a 
colloid cyst: case report. Neurosurgery 37:1200-1203, 1995

11. Cuetter AC, Garcia-Bobadilla J, Guerra LG, et al: Neurocysticercosis: focus on intraventricular disease. Clin Infect Dis 24:157-164, 1997

12. Del Brutto OH, Sotelo J: Albendazole therapy for subarachnoid and ventricular cysticercosis. Case report. J Neurosurg 72:816-817, 1990

13. Del Brutto OH, Sotelo J: Neurocysticercosis: an update. Rev Infect Dis 10:1075-1087, 1988

14. Del Brutto OH, Sotelo J, Roman GC: Therapy for neurocysticercosis: a reappraisal. Clin Infect Dis 17:730-735, 1993

15. Dixon HB, Lipscomb FM: Cysticercosis: an analysis and follow-up of 450 cases. Med Res Spec Rep 299:1-58, 1961

16. Estañol B, Corona T, Abad P: A prognostic classification of cerebral cysticercosis: therapeutic implications. J Neurol Neurosurg Psychiatry 49:1131-1134, 1986

17. Estañol B, Kleriga E, Loyo M, et al: Mechanisms of hydrocephalus in cerebral cysticercosis: implications for therapy. Neurosurgery 13:119-123, 1983

18. Jeeves MA, Simpson DA, Geffen G: Functional consequences of the transcallosal removal of intraventricular tumours. J Neurol Neurosurg Psychiatry 42:134-142, 1979

19. Kelly PJ: Stereotactic third ventriculostomy in patients with nontumoral adolescent/adult aqueductal stenosis and symptomatic hydrocephalus. J Neurosurg 75:865-873, 1991

20. King JS, Hosobuchi Y: Cysticercus cyst of the lateral ventricle. Surg Neurol 7:125-129, 1977

21. Lobato RD, Lamas E, Portillo JM, et al: Hydrocephalus in cerebral cysticercosis. Pathogenic and therapeutic considerations. J Neurosurg 55:786-793, 1981

22. Loyo-Varela M: Surgical treatment of cerebral cysticercosis. Eur Neurol 37:129-130, 1997

23. Loyo-Varela M, del Valle-Robles R, Guinto-Balanzar G, et al: Infestations and the fourth ventricle: cysticercosis, in Cohen AR (ed): Surgical Disorders of the Fourth Ventricle. Cambridge, Mass: Blackwell Science, 1996, pp 397-411

24. Madrazo I, García-Rentería JA, Sandoval M, et al: Intraventricular cysticercosis. Neurosurgery 12:148-152, 1983

25. Madrazo I, Sanchez Cabrera JM, Maldanado Leon JA: Pipette suction for atraumatic extraction of intraventricular cysticercosis cysts. Technical note. J Neurosurg 50:531-532, 1979

26. McCormick GF: Cysticercosis--review of 230 patients. Bull Clin Neurosci 50:76-101, 1985

27. Neal JH: An endoscopic approach to cysticercosis cysts of the posterior third ventricle.

Neurosurgery 36:1040-1043, 1995

28. Obrador S: Cysticercosis cerebri. Acta Neurochir 10:320-364, 1962

29. Pittella JEH: Neurocysticercosis. Brain Pathol 7:681-693, 1997 
30. Proaño JV, Madrazo I, García L, et al: Albendazole and praziquantel treatment in neurocysticercosis of the fourth ventricle. J Neurosurg 87:29-33, 1997

31. Richards FO Jr, Schantz PM, Ruiz-Tiben E, et al: Cysticercosis in Los Angeles County. JAMA 254:3444-3448, 1985

32. Sainte-Rose C, Hoffman HJ, Hirsch JF: Shunt failure. Concepts Pediatr Neurosurg 9:7-20, 1989

33. Sandoval M, Madrazo I, García-Rentería JA, et al: Obstruction of the ventricular catheter of a CSF shunt system due to the own cyst of Taenia solium. Arch Invest Med 21:95-98, 1990

34. Sotelo J: Update: the new ventriculoperitoneal shunt at The Institute of Neurology of Mexico. Surg Neurol 46:19-20, 1996

35. Sotelo J, Marin C: Hydrocephalus secondary to cysticercotic arachnoiditis. A long-term follow-up review of 92 cases. J Neurosurg 66:686-689, 1987

36. Stern WE: Neurosurgical considerations of cysticercosis of the central nervous system. J Neurosurg 55:382-389, 1981

37. Wei GZ, Li CJ, Meng JM, et al: Cysticercosis of the central nervous system. A clinical study of 1,400 cases. Chin Med J 101:493-500, 1988

38. Zee CS, Segall HD, Apuzzo MLJ, et al: Intraventricular cysticercal cysts: further neuroradiologic observations and neurosurgical implications. AJNR 5:727-730, 1984

Manuscript received February 15, 1999.

Accepted in final form March 5, 1999.

Address reprint requests to: Marvin Bergsneider, M.D., Division of Neurosurgery, UCLA, Box 957039, Los Angeles, CA 90095-7039. email: bergsnei@surgery.medsch.ucla.edu. 


\section{QuickTime Movies}
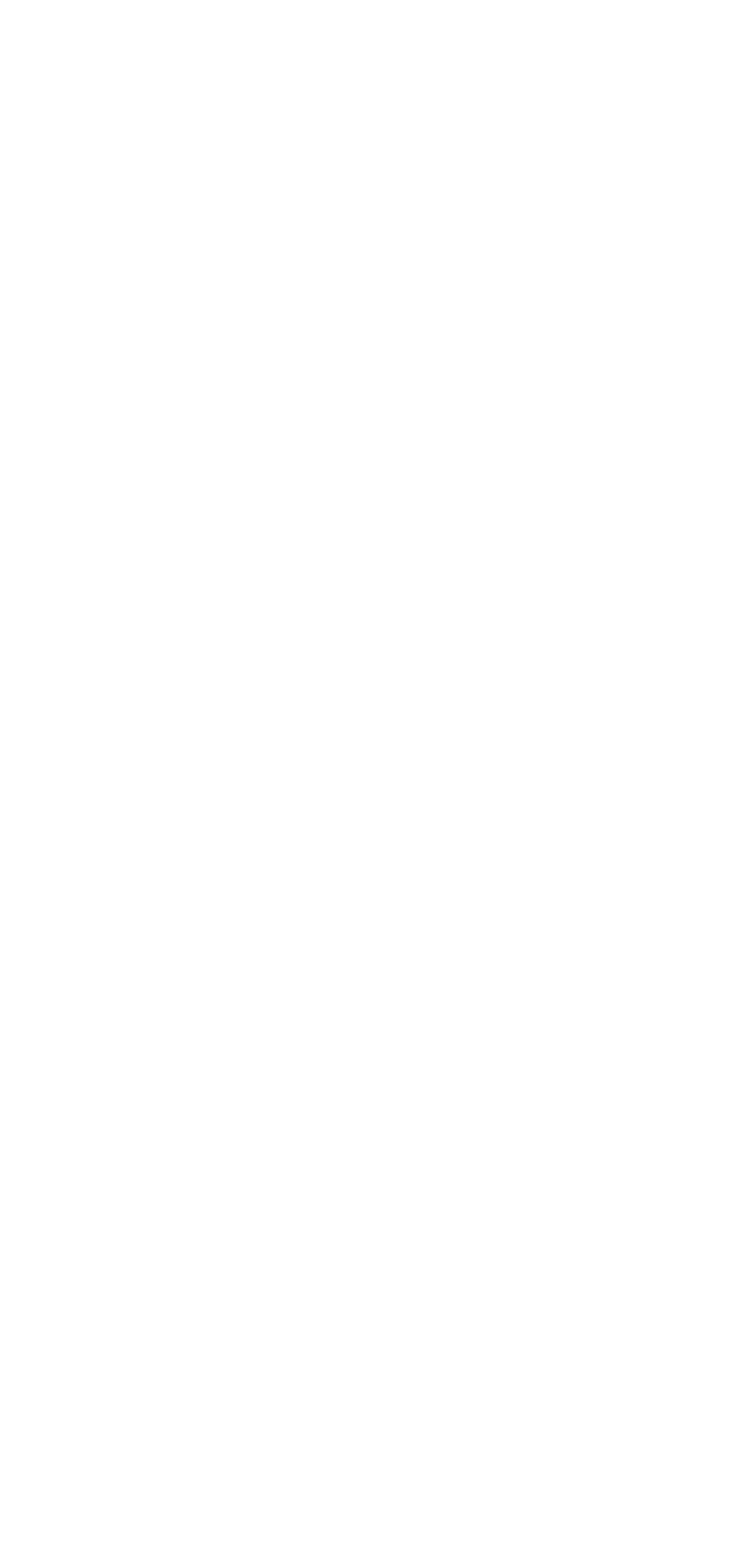